\title{
SOX9 is associated with advanced T-stages of clinical stage II colon cancer in young Mexican patients
}

\author{
ERIK LIZÁRRAGA-VERDUGO ${ }^{1}$, TATIANA GALICIA CARMONA ${ }^{2}$, ROSALÍO RAMOS-PAYAN ${ }^{1}$, \\ MARIANA AVENDAÑO-FÉLIX ${ }^{1}$, MERCEDES BERMÚDEZ ${ }^{1}$, MARYELV PARRA-NIEBLA ${ }^{1}$, \\ CÉSAR LÓPEZ-CAMARILLO ${ }^{3}$, EDITH FERNANDEZ-FIGUEROA ${ }^{4}$, LEONARDO LINO-SILVA ${ }^{5}$, \\ HERMINIA ARVELO SAAVEDRA ${ }^{2}$, ITZEL VELA-SARMIENTO ${ }^{6}$, ROBERTO CÁRDENAS OVANDO ${ }^{7}$, \\ ERIKA RUÍZ-GARCÍA ${ }^{2}$ and MARIBEL AGUILAR-MEDINA ${ }^{1}$ \\ ${ }^{1}$ Faculty of Chemical and Biological Sciences, Autonomous University of Sinaloa, 80010 Culiacán, Sinaloa; \\ ${ }^{2}$ Department of Translational Medicine, National Cancer Institute, 14080 Mexico City; \\ ${ }^{3}$ Oncogenomics Laboratory, Autonomous University of Mexico City, 06720 Mexico City; \\ Departments of ${ }^{4}$ Computational Genomics Laboratories, ${ }^{5}$ Pathology and ${ }^{6}$ Gastrointestinal Tumors, \\ National Cancer Institute, 14080 Mexico City; ${ }^{7}$ School of Engineering and Sciences, \\ Monterrreys' Technologic, 14380 Mexico City, Mexico
}

Received October 20, 2020; Accepted April 12, 2021

DOI: $10.3892 / 01.2021 .12758$

\begin{abstract}
Colorectal cancer (CRC) is one of the most common malignancies worldwide and includes colon cancer (CC) and rectal cancer (RC). Regarding CC, the development of novel molecular biomarkers for the accurate diagnosis and prognosis, as well as the identification of novel targets for therapeutic intervention, are urgently needed. SRY-related high-mobility group box 9 (SOX9), a transcription factor, is involved in development, and has been associated with the progression of human cancer. However, its underlying clinical and functional effects in CRC have not been fully understood. Therefore, the present study aimed to evaluate the clinical and functional relevance of SOX9 expression in CC. The expression of SOX9 in tumor tissues was evaluated in 97 biopsies from Mexican patients with CC with early-stage I and II disease by immunohistochemistry (IHC). In addition, SOX9 silencing in the HCT116 cell line was performed using specific small interfering RNAs, while downregulation efficiency was verified by reverse transcription-quantitative PCR and immunofluorescence. Spheroid-formation assay was carried
\end{abstract}

Correspondence to: Dr Maribel Aguilar-Medina, Faculty of Chemical and Biological Sciences, Autonomous University of Sinaloa, Josefa Ortiz de Domínguez S/N y Avenida de las Américas, 80010 Culiacán, Sinaloa, México

E-mail: maribelaguilar@uas.edu.mx

Dr Erika Ruíz-García, Department of Translational Medicine, National Cancer Institute, Avenida San Fernando 22, Belisario Domínguez Secc 16, Tlalpan, 14080 Mexico City, México

E-mail: betzabe100@yahoo.com.mx

Key words: colon cancer, relapse, SOX9, tumorigenesis out using ultra-low attachment plates. The IHC results showed that SOX9 was upregulated in patients with stage II (91\%) and advanced T3 stage (67\%) CC. Interestingly, higher SOX9 expression was associated with clinical stage, tumor size and tumor location. Furthermore, increased SOX9 expression was found in relapsed cases with local tumors; however, it was not associated with increased survival probability. Additionally, functional analysis indicated that SOX9 silencing significantly attenuated the sphere-formation capability of HCT116 cells. The present study was the first to evaluate the expression levels of SOX9 in Mexican patients diagnosed with early-stage CC. The aforementioned findings indicated that high SOX9 expression could play an important role in tumorigenesis and be associated with advanced T-stages of clinical-stage II patients, but not with relapse-free survival.

\section{Introduction}

Colorectal cancer (CRC) is one of the most common types of cancer, with 1.8 million cases and 862,000 deaths worldwide, only during 2018 (1). In total, $\sim 2 / 3$ of CRC cases are associated with colon cancer (CC) and the rest with rectal cancer (RC). In addition, CRC is the third most commonly occurring type of cancer in men and the second in women in the world (2). The incidence and mortality rates of CRC are increasing in younger individuals for whom screening is limited and key symptoms may be not obvious. The aforementioned finding is very important since for the majority of patients with cancer, the 1- and 5-year survival rate is much higher when cancer is diagnosed at the early stages of the disease (3). Mexico is one of the principal countries with the highest incidence of CRC in young individuals, with a rate of $22.8 \%$ among patients $<40$ years old $(4,5)$.

The development of CRC is a multifactorial and multistep process involving different genomic and epigenetic 
modifications. The majority of CRC cases are sporadic and develop slowly for over a decade through the adenoma-carcinoma sequence (6). Although substantial progress has been made in the treatment and understanding of the molecular mechanisms involved in CRC in recent years, the overall survival (OS) rate remains relatively low compared with other types of cancer $(7,8)$.

Emerging evidence has suggested that the Wnt pathway is involved in the maintenance of the self-renewal capacity of stem cells of the gastrointestinal tract (9). Paneth cells are a highly specialized epithelial cell type located at the crypts, which serve a critical role in controlling intestinal stem cell niche, and supporting crypt base columnar cells and the regeneration of absorptive and secretory cell types $(10,11)$. SRY-related high-mobility group box 9 (SOX9) is a member of the SOX family of transcription factors, and is known to act as a regulator in a variety of developmental processes such as male sex determination, chondrogenesis, neurogenesis and neural crest development (12). In the healthy colon, SOX9 is expressed in stem/progenitor and Paneth cells by the transcriptional effector of the Wnt pathway, namely the $\beta$-catenin/transcription factor 4 (TCF4) complex (13). Mutations in important components of the Wnt pathway, such as the tumor suppressor adenomatous polyposis coli (APC) and the multifunctional $\beta$-catenin gene, have been reported in the majority of CC cases (14). These mutations result in the stabilization of $\beta$-catenin that constantly interacts with TCF4, thus leading to constitutive transcription of TCF4-target genes, such as SOX9, eventually promoting the development of $\mathrm{CC}$ through transformation of the colonic epithelium (15). It has been reported that mutations in the SOX9 gene, such as recurrent distal truncating and frameshift or nonsense mutations, result in SOX9 overexpression in $11 \%$ of CC cases. In addition, SOX9 mutations may coexist with KRAS mutations and wild-type tumor protein 53 status (16).

Despite the importance of SOX9 in maintaining colon homeostasis and stemness properties within the crypts (13), it has been ambiguously reported as both an oncogene and tumor suppressor gene. As an oncogene, overexpression of SOX9 in vitro and in vivo has been associated with different pro-oncogenic properties in CRC, such as promotion of proliferation, inhibition of senescence, and collaboration with other oncogenes in cancer development (17). Interestingly, a study suggested that SOX9 could serve as a marker of CRC progression and/or differentiation, since it could negatively regulate the gene expression of CDX2 and mucin 2, oligomeric mucus/gel-forming via $\beta$-catenin (18). Moreover, a previous study has suggested that the increased levels of SOX9 are strongly associated with poor prognosis in CRC (19). SOX9 overexpression also promoted $\mathrm{S} 100 \mathrm{P}$ upregulation, which in turn enhanced the invasiveness and metastasis of CC cells via activating the receptor for advanced glycation end products/ERK signaling and promoting epithelial-mesenchymal transition (EMT) (20). In this regard, SOX9 could regulate hypoxia-induced ubiquitin-specific protease 47 upregulation to promote EMT and metastasis of CRC cells (21). Additionally, another study demonstrated that the increased secretion of TGF- $\beta$ by tumor microenvironment-associated macrophages upregulated SOX9 expression and facilitated EMT (22).
Furthermore, it has been reported that high levels of SOX9 enhance the invasion potential of CRC cells by providing stemness properties (23), and are associated with decreased survival rate and adverse prognosis, thus supporting its use as a potential diagnostic and prognostic marker in CRC in the Spanish population, via deregulating the BMI1 oncogene (24).

As a tumor suppressor, SOX9 is associated with the human carcinoembryonic antigen (CEA) gene, which induces apoptosis (25) and the CEA-related cell adhesion molecule 1 (26) in the human CC cell line HT29-16E. Interestingly, low expression of SOX9 was associated with a higher relapse risk in stage II CRC cases in a Denmark population (27).

CRC is classified based on three important points combined into an overall stage, namely local invasion depth (T stage), lymph node involvement ( $\mathrm{N}$ stage) and presence of distant metastases (M stage) (7). However, CC shows high tumor heterogeneity among patients, even at the same TNM stage. Nowadays, prognostic markers, such as hypoalbuminemia are used to predict poor surgical outcomes of colon cancer; hypoalbuminemia is a poor prognosis factor for long-term survival of colon cancer after curative surgery (28) and albumin level $<3.5 \mathrm{~g} / \mathrm{dl}$ predict a poor survival chance for patients with colorectal carcinoma (29). For this reason, the pathological approach should be complemented with molecular classification using diagnostic and prognostic biomarkers to provide the appropriate therapy (30). Although populations growing in different environments show some similarities in the instauration of $\mathrm{CC}$, they also present with heterogeneity in the biomarkers associated with the onset of the disease. Therefore, the present study aimed to evaluate the clinical value of SOX9 expression in CC.

\section{Materials and methods}

Patients and tumor tissue samples. An observational, descriptive, and retrospective study was conducted between January 2012 and June 2017. A total of 97 adult patients (48 male and 49 female; mean age $\pm \mathrm{SD}, 56.2 \pm 14.45$ years; age range, 18-90 years) were diagnosed with early-stage I and II colon cancer at the National Cancer Institute of Mexico. Tissue samples were obtained from all patients during surgical treatment and were then paraffin-embedded. The study protocol was approved by the Institutional Review Board of the National Cancer Institute of Mexico (permit no. Rev/42/16) and due to its retrospective nature, patient informed consent was not needed. The clinicopathological features of patients were recorded and evaluated. According to Vera et al (31), minimal follow-up should be between 3-6 months during the first 5 years, thus, patients who were lost to follow-up for $>6$ months were excluded. The median follow-up period for all patients was 66 months.

Immunohistochemistry (IHC). Paraffin-embedded tissues were cut into 3- $\mu \mathrm{m}$ thick slices and the SOX9 expression levels were determined by IHC. Briefly, tissue slices were rehydrated and antigenically reactivated in citrate buffer $(0.01 \mathrm{M}$ citric acid, $0.01 \mathrm{M}$ sodium citrate) for $10 \mathrm{~min}$ at $95^{\circ} \mathrm{C}$. Tissues were then washed twice with $1 \mathrm{X}$ PBS. Subsequently, IHC was carried out using the Mouse and Rabbit Specific HRP Detection IHC kit (cat. no. ab-93686; Abcam) following the 
manufacturer's instructions. Tissue endogenous peroxidase was blocked following slice incubation with hydrogen peroxide for $10 \mathrm{~min}$ at room temperature followed by washing twice with 1X PBS. Non-specific antigenic sites were blocked by a protein blocking solution for $10 \mathrm{~min}$ at room temperature, and the tissue samples were washed once followed by incubation with a polyclonal rabbit SOX9 antibody (cat. no. ab185966; Abcam; $1: 100$ ) diluted in $0.01 \%$ Triton X-100 and 0.1\% BSA overnight at $4^{\circ} \mathrm{C}$. The slides were then washed three times with $1 \mathrm{X}$ PBS, incubated with enhancer solution for $10 \mathrm{~min}$ at room temperature, washed again once and incubated with the rabbit secondary antibody (cat. no. ab185966; Abcam; 1:800) for $30 \mathrm{~min}$ at room temperature. Following incubation with the secondary antibody, the tissues were washed, and incubated for $5 \mathrm{~min}$ at room temperature with the DAB Black kit (cat. no. BR140 H, L; Biocare Medical, LLC). The slides were counterstained with eosin for $5 \mathrm{sec}$ and mounted using the Aqua Mounter Solution (cat. no. BSB0091; Bio SB). Digital images of the tissue sections were captured under a light microscope (magnification, x400 using the color AxioCam MRc5 camera (Zeiss). SOX9 expression was evaluated at the invasive front of the tumor by a pathologist (LLS) who was blinded to the clinical data. The percentage score of positive tumor nuclei was defined as: 0 (0-5\%), 1 (>5-25\%), 2 (>25-50\%), 3 (>50-75\%) and $4(>75 \%)$. Signal intensity was scored as follows: 0 (negative), 1 (low signal), 2 (moderate signal) and 3 (high signal). The overall score for SOX 9 expression was determined by multiplying the score of positive nuclei with that for signal intensity (32). SOX9 expression was considered as 'low' when the overall score was 0-4 and as 'high' when the overall score was 4-12.

Cell culture. The human CC HCT116 cell line and the human normal colon cell line CCD-18co were purchased from the American Type Culture Collection. HCT116 cells were cultured in DMEM/F12 (Gibco; Thermo Fisher Scientific, Inc.) supplemented with 10\% FBS (Gibco; Thermo Fisher Scientific, Inc.) and $1 \%$ penicillin/streptomycin. CCD-18co cells were maintained in DMEM (Gibco; Thermo Fisher Scientific, Inc.) supplemented with $10 \% \mathrm{FBS}, 1 \%$ penicillin/streptomycin and $1 \%$ non-essential amino acids. Both cell lines were incubated at $37^{\circ} \mathrm{C}$ in a humidified atmosphere containing $5 \% \mathrm{CO}_{2}$.

SOX9 silencing using small interfering RNAs (siRNAs). A total of $3 \times 10^{5}$ HCT116 cells were seeded into 6-well plates and when confluence reached $70 \%$, cells were transfected with 30 nM Silencer Select siRNA (cat. no. s532658; targeted exon 3, siRNA location 1243; Thermo Fisher Scientific, Inc.) specific to SOX9 (HCT116-siSOX9) and a negative control (HCT116-Scr, cat. no. 4404021), using the Lipofectamine ${ }^{\circledR}$ RNAiMAX reagent (Invitrogen; Thermo Fisher Scientific, Inc.) according to the manufacturer's protocol. Transfection with a scrambled sequence served as control in functional assays. The efficiency of SOX9 silencing was verified $24 \mathrm{~h}$ post transfection.

$R N A$ purification and reverse transcription-quantitative $P C R$ (RT-qPCR). Total RNA was extracted from transfected cells using the TRIzol ${ }^{\circledR}$ reagent (Thermo Fisher Scientific, Inc) and transcribed into cDNA using the High-Capacity cDNA Reverse
Transcription kit (Thermo Fisher Scientific, Inc.), following the manufacturer's protocol: $25^{\circ} \mathrm{C}$ for $10 \mathrm{~min}, 37^{\circ} \mathrm{C}$ for $2 \mathrm{~h}$ and $85^{\circ} \mathrm{C}$ for $5 \mathrm{~min}$. qPCR was carried out using the TaqMan Gene Expression Assay for SOX9 (cat. no. Hs00165814_m1; Applied Biosystems; Thermo Fisher Scientific, Inc.; amplicon length 102, exon boundary 2-3) and TaqMan Universal PCR Master mix (Thermo Fisher Scientific, Inc.). The PCR reactions were incubated at $50^{\circ} \mathrm{C}$ for $2 \mathrm{~min}, 95^{\circ} \mathrm{C} 10 \mathrm{~min}$, followed by 40 cycles of $95^{\circ} \mathrm{C}$ for $15 \mathrm{sec}$ and $60^{\circ} \mathrm{C}$ for $1 \mathrm{~min}$. PCR analysis was carried out in triplicate and gene expression was analyzed using the $2^{-\Delta \Delta C q}$ method (33). ACTB (cat. no. Hs01060665_g1, amplicon length 63, exon boundary 2-3) was used as the endogenous control.

Immunofluorescence analysis. Immunofluorescence was performed $48 \mathrm{~h}$ post-transfection as previously described (34). Briefly, cells were washed with ice-cold PBS and fixed in $4 \%$ p-formaldehyde for $10 \mathrm{~min}$. Then, the samples were washed three times with PBS and permeabilized with $0.1 \%$ Triton X-100 for $10 \mathrm{~min}$. Following washing and blocking with $22.52 \mathrm{mg} / \mathrm{ml}$ glycine and $1 \% \mathrm{BFS}$, samples were hybridized with rabbit anti-human SOX9 antibody (dilution, 1:200; cat. no. ab185966; Abcam) for $1 \mathrm{~h}$ at room temperature, washed again and incubated with donkey anti-rabbit IgG Alexa 647 secondary antibody (dilution, 1:1,000; cat. no. ab150075; Abcam) for $1 \mathrm{~h}$ at room temperature. Finally, the samples were washed and mounted using Fluoroshield with DAPI (Sigma-Aldrich; Merck KGaA). Images were captured at a magnification of $\mathrm{x} 40$ under the Leica LSCM SP8 (Leica Microsystems, Inc.) microscope.

Sphere-formation assay. HCT116 and HCT116-siSOX9 cells were seeded at a density of $4 \times 10^{4}$ cells/well into Ultra-Low Attachment 6-well plates (Costar; Corning Inc.). Following incubation for $72 \mathrm{~h}$, sphere-formation capacity was evaluated under an inverted light microscope at a magnification of x10.

Statistical analysis. For clinical and experimental data, categorical variables were compared by $\chi^{2}$ test and Fisher's exact test was used for relapsed patients, while continuous variables were analyzed using t-test or ANOVA followed by Bonferroni's post hoc with the GraphPad Prism 8.0 software (GraphPad Software, Inc.). For survival analysis, the OS was defined as the interval between surgery and the last visit or death. In addition, relapse-free survival (RFS) was defined as the interval between surgery and the local or distant relapse. The estimate curves for 3-year OS and RFS were obtained by the Kaplan-Meier method and the differences between groups were determined by log-rank test. Statistical analyses were performed using the STATA v.12.0 software (Stata Corp.). $\mathrm{P}<0.05$ was considered to indicate a statistically significant difference.

\section{Results}

SOX9 expression is associated with clinical stage, tumor size and tumor location in CC. SOX9 has been identified as an oncogene in several types of cancer, and is therefore considered to be a possible biomarker of aggressive disease (35). Herein, the clinical value of SOX9 expression was evaluated 
Table I. Overall patient characteristics.

\begin{tabular}{|c|c|c|c|}
\hline Characteristics & $\begin{array}{c}\text { Low SOX9 } \\
\text { expression } \\
\mathrm{n}=52, \mathrm{n}(\%)\end{array}$ & $\begin{array}{c}\text { High SOX9 } \\
\text { expression } \\
\mathrm{n}=45, \mathrm{n}(\%)\end{array}$ & P-value \\
\hline $\begin{array}{l}\text { Mean of age } \pm S D \text {, } \\
\text { years }\end{array}$ & $60.7 \pm 14.5$ & $51.7 \pm 14.4$ & 0.003 \\
\hline Age, years & & & \\
\hline$\leq 40$ & $4(8)$ & $11(24)$ & 0.046 \\
\hline$>40$ & $48(92)$ & $34(76)$ & \\
\hline Sex & & & 0.913 \\
\hline Male & $26(50)$ & $22(49)$ & \\
\hline Female & $26(40)$ & $23(51)$ & \\
\hline BMI & & & 0.34 \\
\hline Malnutrition & $1(2)$ & $3(6)$ & \\
\hline Normal & $26(50)$ & $27(60)$ & \\
\hline Overweight & $20(38)$ & $13(29)$ & \\
\hline Obesity & $5(10)$ & $2(5)$ & \\
\hline Albumin level & & & 0.065 \\
\hline$<3.5$ & $16(30)$ & $23(51)$ & \\
\hline$>3.5$ & $36(70)$ & $22(49)$ & \\
\hline Clinical stage & & & $<0.001$ \\
\hline I & $30(58)$ & $4(9)$ & \\
\hline II & $22(42)$ & $41(91)$ & \\
\hline T stage & & & $<0.001$ \\
\hline $\mathrm{T} 1$ & $8(15)$ & $0(0)$ & \\
\hline $\mathrm{T} 2$ & $22(42)$ & $4(9)$ & \\
\hline $\mathrm{T} 3$ & $15(29)$ & $30(67)$ & \\
\hline $\mathrm{T} 4$ & $7(14)$ & $11(24)$ & \\
\hline Histological type & & & 0.74 \\
\hline Mucinous & $8(15)$ & $9(20)$ & \\
\hline Not mucinous & $44(85)$ & $36(80)$ & \\
\hline Histological grade & & & 0.16 \\
\hline 1 & $21(40)$ & $12(27)$ & \\
\hline 2 & $20(39)$ & $26(58)$ & \\
\hline 3 & $11(21)$ & $7(15)$ & \\
\hline Tumor side & & & 0.048 \\
\hline Right & $22(42)$ & $29(64)$ & \\
\hline Left & $30(58)$ & $16(36)$ & \\
\hline Intestinal perforation & & & 0.81 \\
\hline Yes & $4(8)$ & $2(5)$ & \\
\hline No & $48(92)$ & $43(95)$ & \\
\hline Intestinal occlusion & & & 0.98 \\
\hline Yes & $8(15)$ & $7(16)$ & \\
\hline No & $44(85)$ & $38(84)$ & \\
\hline Lymphovascular invasion & & & 0.87 \\
\hline Yes & $11(21)$ & $8(18)$ & \\
\hline No & $41(79)$ & $37(82)$ & \\
\hline Perineural invasion & & & 0.14 \\
\hline Yes & $1(2)$ & $5(11)$ & \\
\hline No & $51(98)$ & $40(89)$ & \\
\hline
\end{tabular}

SOX9, SRY-related high-mobility group box 9; BMI, body mass index.

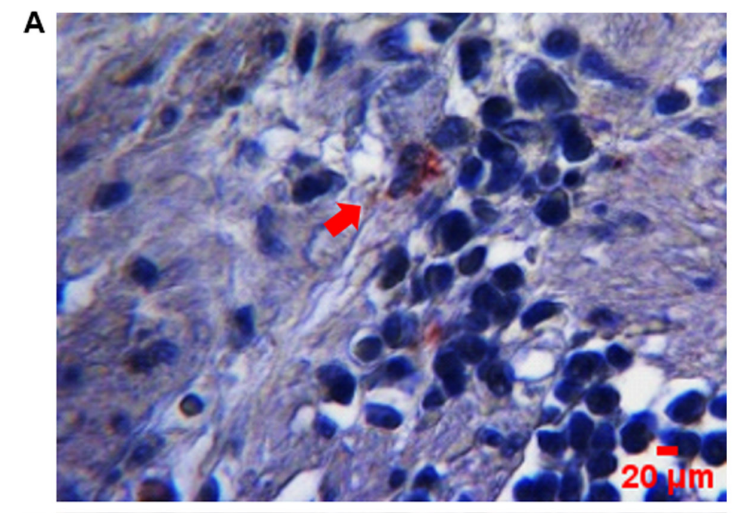

$\mathbf{B}$

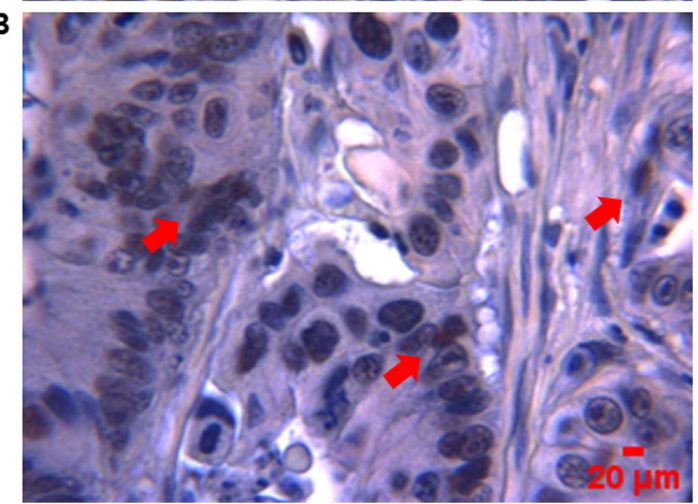

Figure 1. SOX9 expression by IHC in CC tumors. Micrographs showing representative images of (A) low and (B) high SOX9 expression levels. Immunostaining in tissues was visualized at a magnification of X400 (scale bar, $20 \mu \mathrm{m}$ ). Red arrows indicate positive nuclei for SOX9 staining. SOX9, SRY-related high-mobility group box 9; IHC, immunohistochemistry; CC, colon cancer.

in CC samples. The clinical and pathological features from the 97 patients recruited in this study are summarized in Table I. The data showed that SOX9 immunoreactivity was predominantly located in the nuclei of tumor cells (Fig. 1). High SOX9 expression was observed in $47 \%$ of tumors, while low one in 53\% (Fig. 2A). Patients $<40$ years exhibited higher SOX9 expression compared with those $>40$ years $(\mathrm{P}<0.046)$, suggesting that SOX9 could be important for the early onset of CC (Fig. 2B). This age cut-off was selected given the epidemiological data showed by Ahnen et al (5), where more than $11 \%$ of colon cancer and 18\% of rectal cancer have a young-onset, occurring in individuals younger than 50 years and more importantly, by the data showed by Rojas-Puente et al (4), where CRC in Mexican young people less than 40 years old, shows a disease characterized by biological aggressiveness, with unique features such as localization, adverse histologic factors, not associated with prior or concomitant adenomas, advanced stage at diagnosis, and worse prognosis. In addition, SOX9 expression was not associated with sex (Fig. 2C); however, it was positively associated with intestinal tumor location since its high expression was predominant in the right side $\left(\mathrm{P}<0.048\right.$; Fig. 2D). Interestingly, $\chi^{2}$ test showed, that in the high SOX9 expression group, $91 \%$ of patients corresponded to the disease stage II $(\mathrm{P}<0.001)$ and $67 \%$ to the advanced T3 stage $(\mathrm{P}<0.001)$. This finding indicated that SOX9 could be involved in tumor progression, size and extension (Fig. 3).

SOX9 expression is associated with local site recurrence. Relapse occurred in $12.4 \%$ of patients during follow-up, 
Table II. Characteristics of relapsed patients.

\begin{tabular}{llclccc}
\hline Adjuvant & \multicolumn{1}{c}{ Relapse site } & Age, years & Sex & Stage & Tumor location & RFS, months \\
\hline Yes (fluoropyrimidine) & Local & 66 & M & IIA & L & $29 \uparrow$ \\
(N=8) & Local & 59 & F & IIA & L & $19 \uparrow$ \\
& Local & 59 & F & IIA & R & $8 \uparrow$ \\
& Local & 46 & M & IIB & R & $10 \uparrow$ \\
& Retroperitoneum & 72 & F & IIB & L & $29 \downarrow$ \\
& Retroperitoneum & 74 & M & IIA & L & $40 \downarrow$ \\
& Liver & 57 & F & IIB & R & $22 \downarrow$ \\
No (N=4) & Local & 64 & F & IIA & R & $11 \uparrow$ \\
& Liver & 86 & F & I & L & $9 \downarrow$ \\
& Liver & 51 & F & IIB & R & $13 \downarrow$ \\
& Local & 45 & M & I & R & $16 \downarrow$ \\
& Local & 54 & F & I & L & $6 \downarrow$ \\
\hline
\end{tabular}

SOX9, SRY-related high-mobility group box 9; RFS, relapse-free survival; L, left; R, right; $\uparrow$, high SOX9 expression; $\downarrow$, low SOX9 expression; $\mathrm{M}$, male; F, female.

A
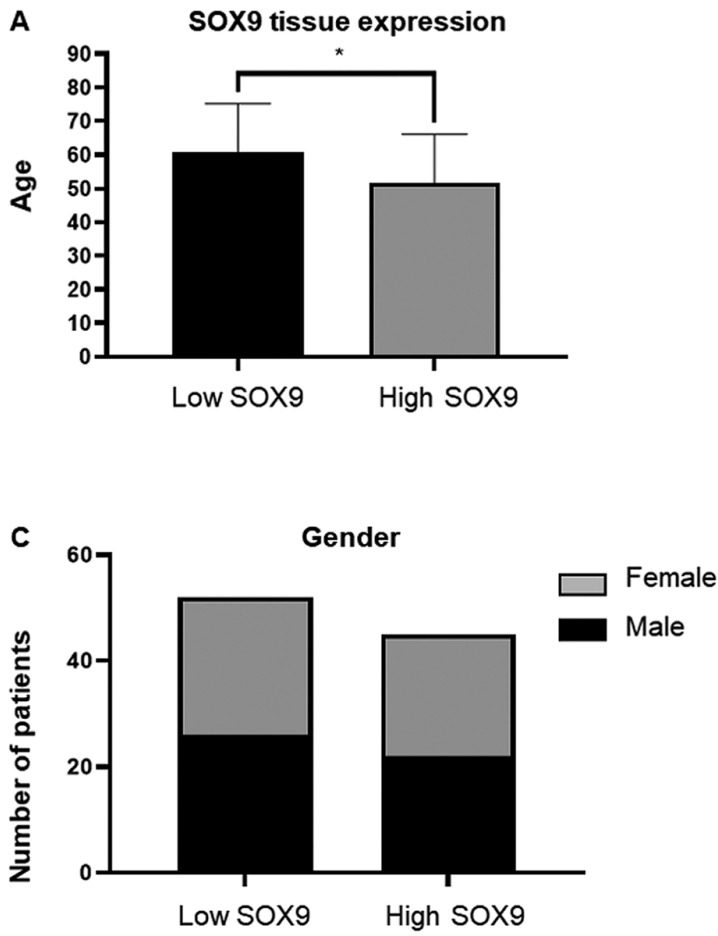

B
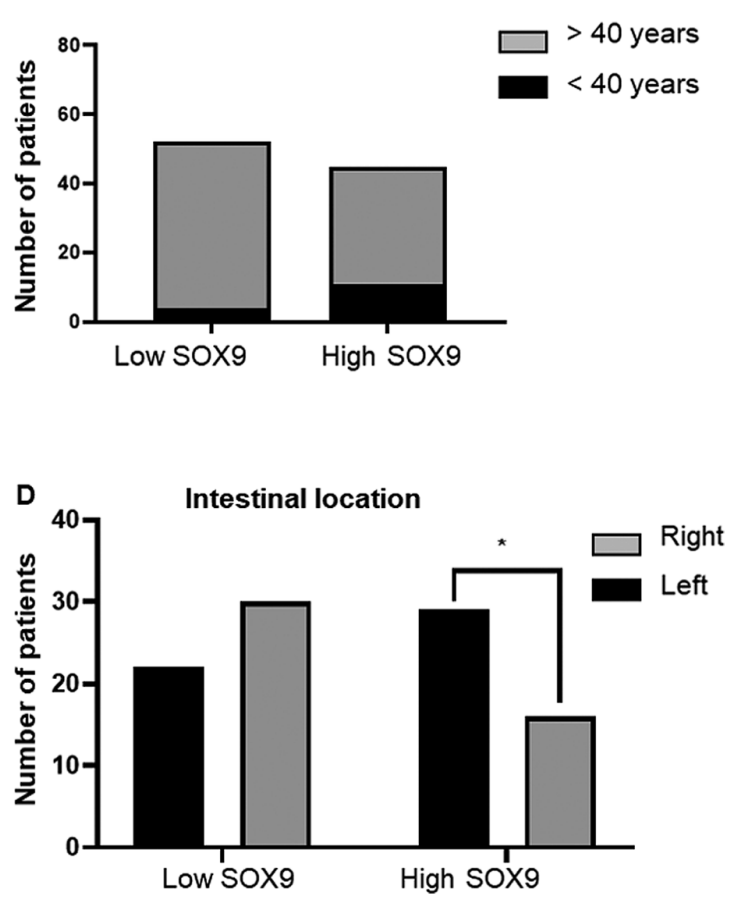

Figure 2. Association of SOX9 expression with clinical variables. (A) A total of $47 \%$ of tumor samples exhibited low SOX9 expression. (B) Patients $>40$ years showed higher SOX9 expression when compared with those over 40 years-old $(\mathrm{P}=0.046)$. (C) There were no differences in SOX9 expression between male and females. (D) There was a higher incidence of right-side tumors $(52 \%)$ in the high SOX9 expression group $(\mathrm{P}=0.048) .{ }^{*} \mathrm{P}<0.05$. SOX9, SRY-related high-mobility group box 9.

while $3 \%$ of them died. The median RFS was 17 months (range, 4-39 months). The characteristics of the relapsed patients are illustrated in Table II. Interestingly, in the case of relapsed patients that received adjuvant therapy $(66.7 \%)$, all with local relapse $(62.5 \%)$ showed tumors with high SOX9 expression levels; while, in those without chemotherapy (33.3\%), all with local $(50 \%)$ and liver $(50 \%)$ relapse showed low SOX9 expression levels. However, due to the low number of cases no statistically significant association was obtained by Fisher's exact test (Table II; Fig. 4). Additionally, SOX9 expression levels were not associated with survival probability, neither in global patients $(P<0.66)$ nor in relapsed ones $(P<0.21$; Fig. 5$)$.

SOX9 silencing inhibits colonosphere formation. To investigate SOX9 effects in $\mathrm{CC}$, its expression was knocked down using specific siRNA targeting SOX9. The results demonstrated that the HCT116 cell line overexpressed SOX9 ( 180 fold) when compared with the non-tumorigenic colon cell line CCD-18Co $(\mathrm{P}<0.001$; Fig. 6A). Following transfection of HCT116 cells with SOX9-siRNA, SOX9 expression was decreased by $\sim 80 \%$ 
A

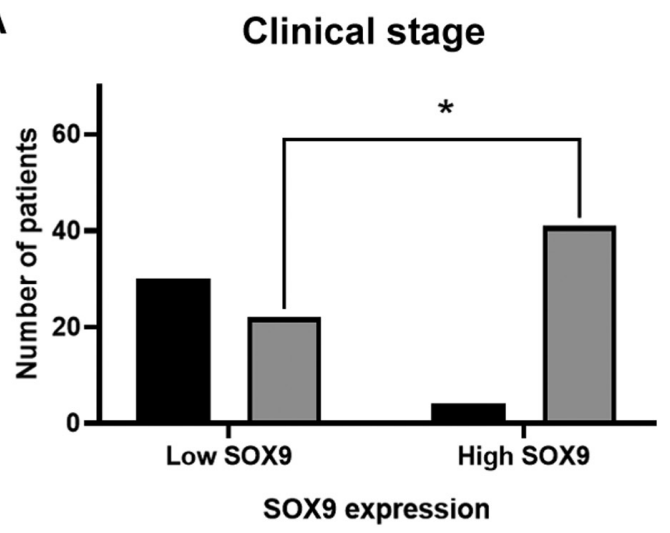

B

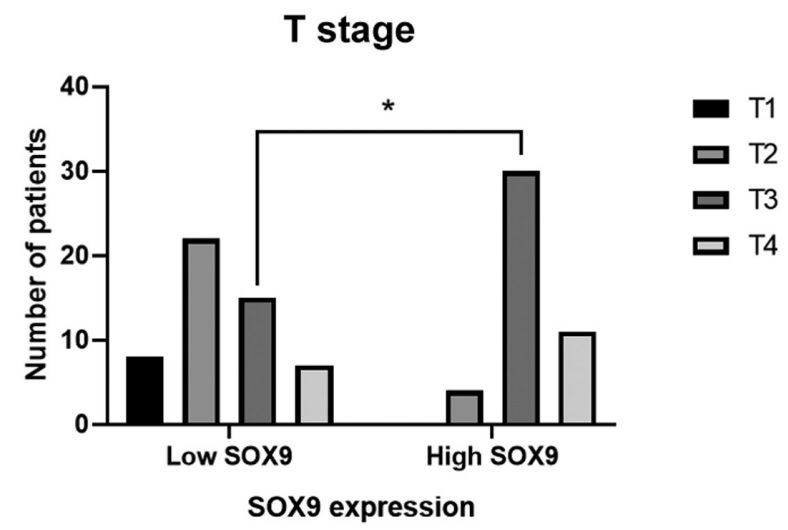

Figure 3. SOX9 expression is associated with clinical and T stages. (A) Patients with CC stage II showed higher SOX9 expression $(\mathrm{P}<0.001)$. Similarly, patients in the high SOX9 expression group exhibited higher incidence of T3 stage $(\mathrm{P}<0.001)$. $\mathrm{P}<0.05$. SOX9, SRY-related high-mobility group box 9.

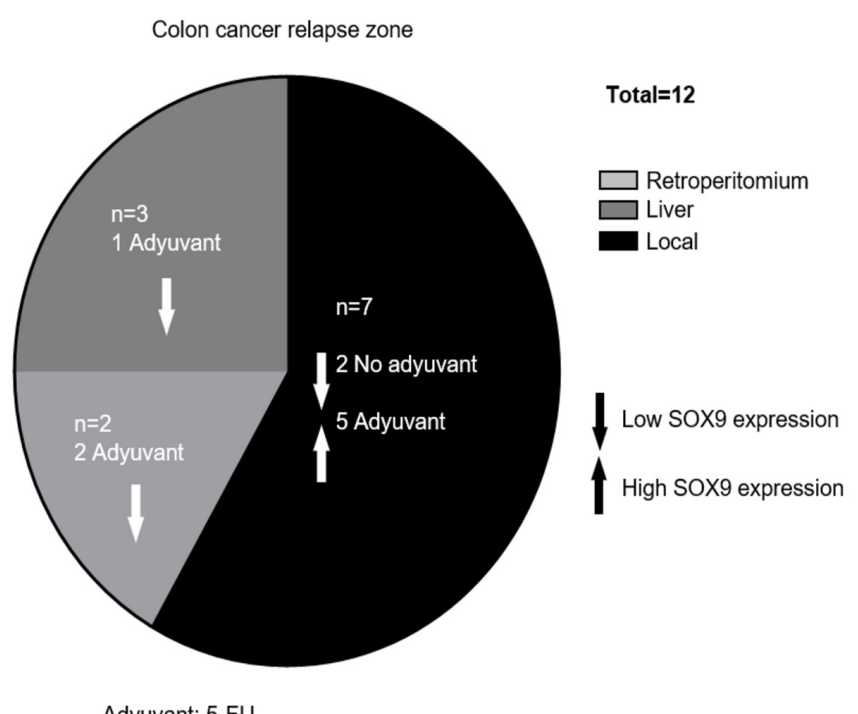

Figure 4. Relapse in patients. The main relapse sites were locally (58\%). A total of 5 patients with local relapse had high SOX 9 expression, and were treated with 5 -FU. Only $25 \%$ of patients presented distant relapse. SOX9, SRY-related high-mobility group box 9; 5-FU, 5-fluorouracil.

$(\mathrm{P}<0.002$; Fig. 6B). Silencing efficiency was also confirmed at the protein level by immunofluorescence assays. The results showed that SOX9 was predominantly located in the cell nuclei and its expression was significantly downregulated in
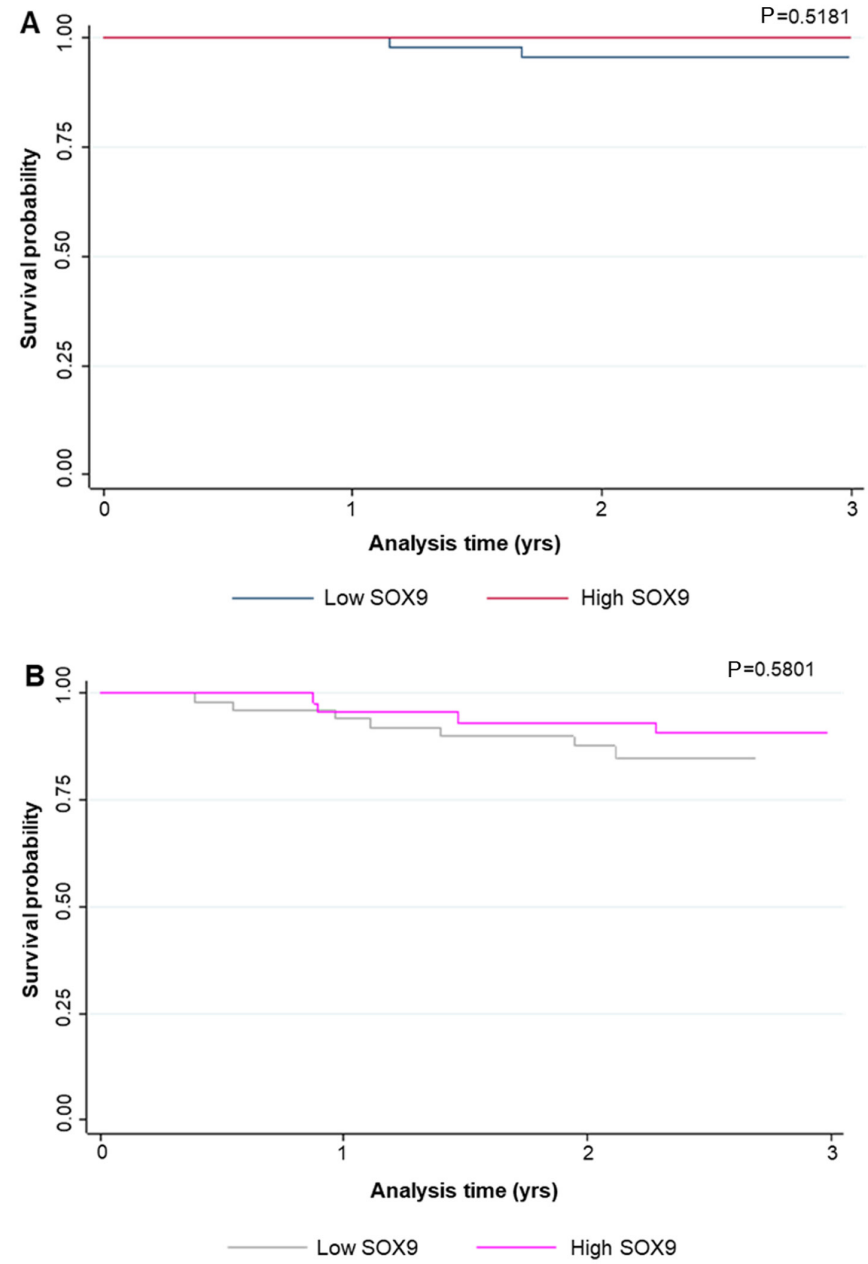

Figure 5. Survival analysis. The effect of high and low SOX9 expression on (A) OS and (B) RLS of patients with stage I-II CC. SOX9, SRY-related high-mobility group box 9; OS, overall survival; RLS, relapse-free survival.

cells transfected with SOX9-siRNA (Fig. 6C). In addition, HCT116 cells were able to generate solid and well-defined colonospheres following incubation for $72 \mathrm{~h}$ in ultra-low attachment plates. On the other hand, SOX9-deficient HCT116 cells showed labile cellular aggregates and a significantly reduced number of colonospheres (Fig. 7).

\section{Discussion}

The present study was the first to evaluate the expression of SOX9 in Mexican patients diagnosed with early-stage colon cancer. A limitation of the study was that samples were only obtained from one hospital. Nevertheless, this national hospital attends patients from all states of the center of the country. Herein, $20 \%$ of all patients were $<40$ years old.

The significance of the current study is based on the fact that in recent years $\mathrm{CC}$ has been diagnosed in younger individuals, increasing by $2 \%$ each year (36). In this regard, it has been reported that early-onset CRC can be caused by APC mutations in combination with environmental factors that may have an impact on epigenetic mechanisms modulating SOX9 expression in the intestinal epithelium (37). Nonetheless, in other studies on diverse types of cancer, including $\mathrm{CC}$, it has been reported that age is not associated with SOX9 expression $(19,27,38,39)$. 

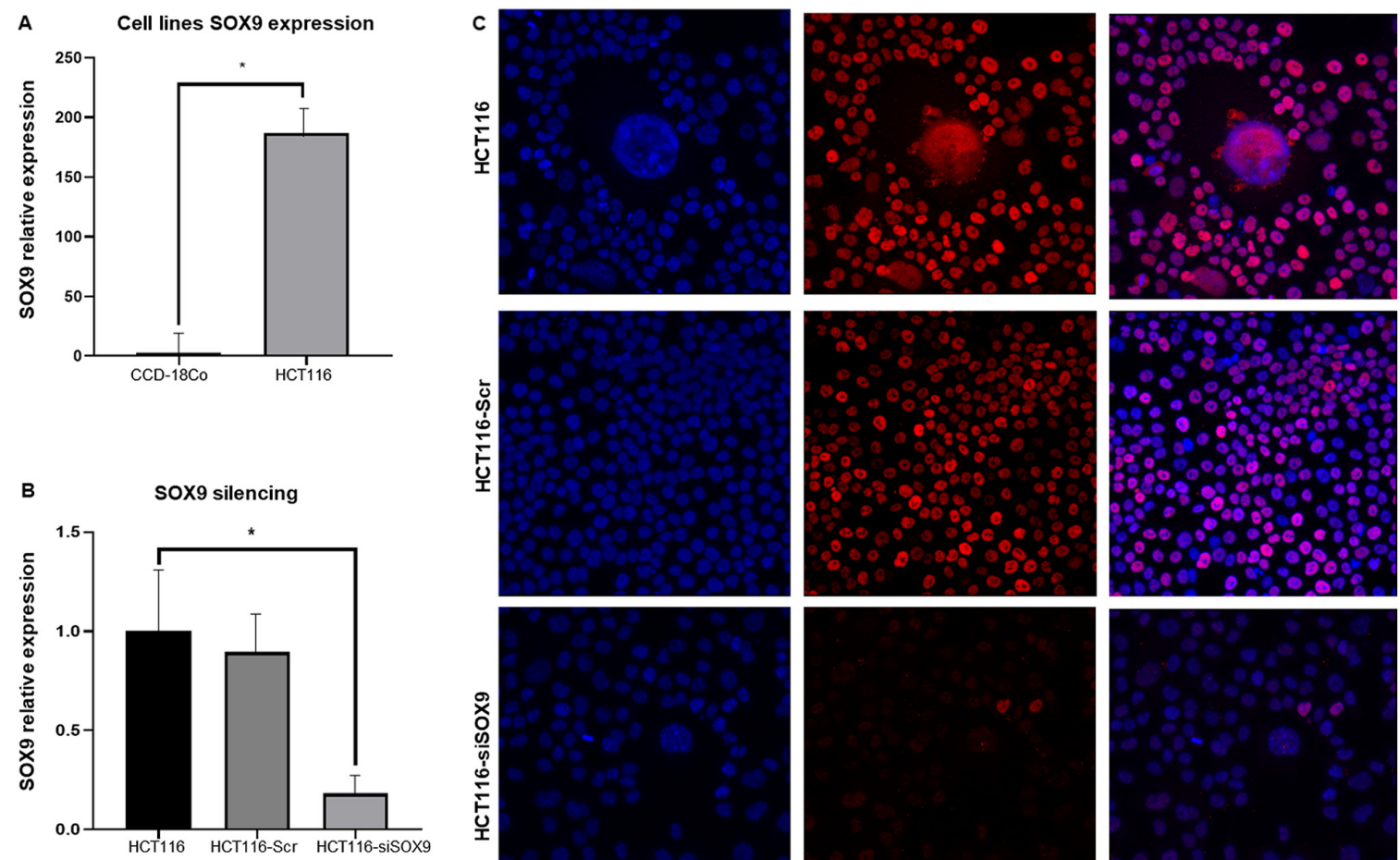

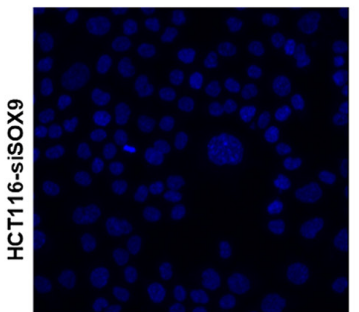

DAPI

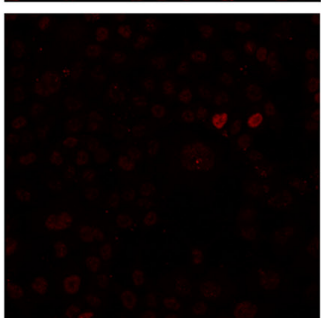

sox9

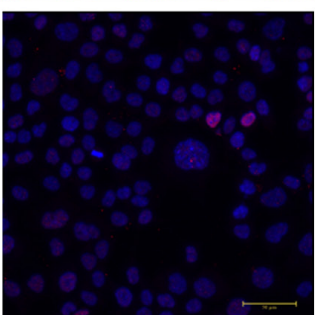

Merged

Figure 6. SOX9 expression and silencing. (A) SOX9 was upregulated in the HCT116 cell line compared with the normal colon cell line CCD18co, as verified by RT-qPCR ( $\mathrm{P}=0.001$ ). (B) Following silencing of SOX9 in HCT116 cells, its expression was reduced by up to $80 \%$ ( $\mathrm{P}=0.002)$. (C) SOX9 silencing at the protein level was verified by immunofluorescence assay. ${ }^{*} \mathrm{P}<0.05$. SOX9, SRY-related high-mobility group box 9 .
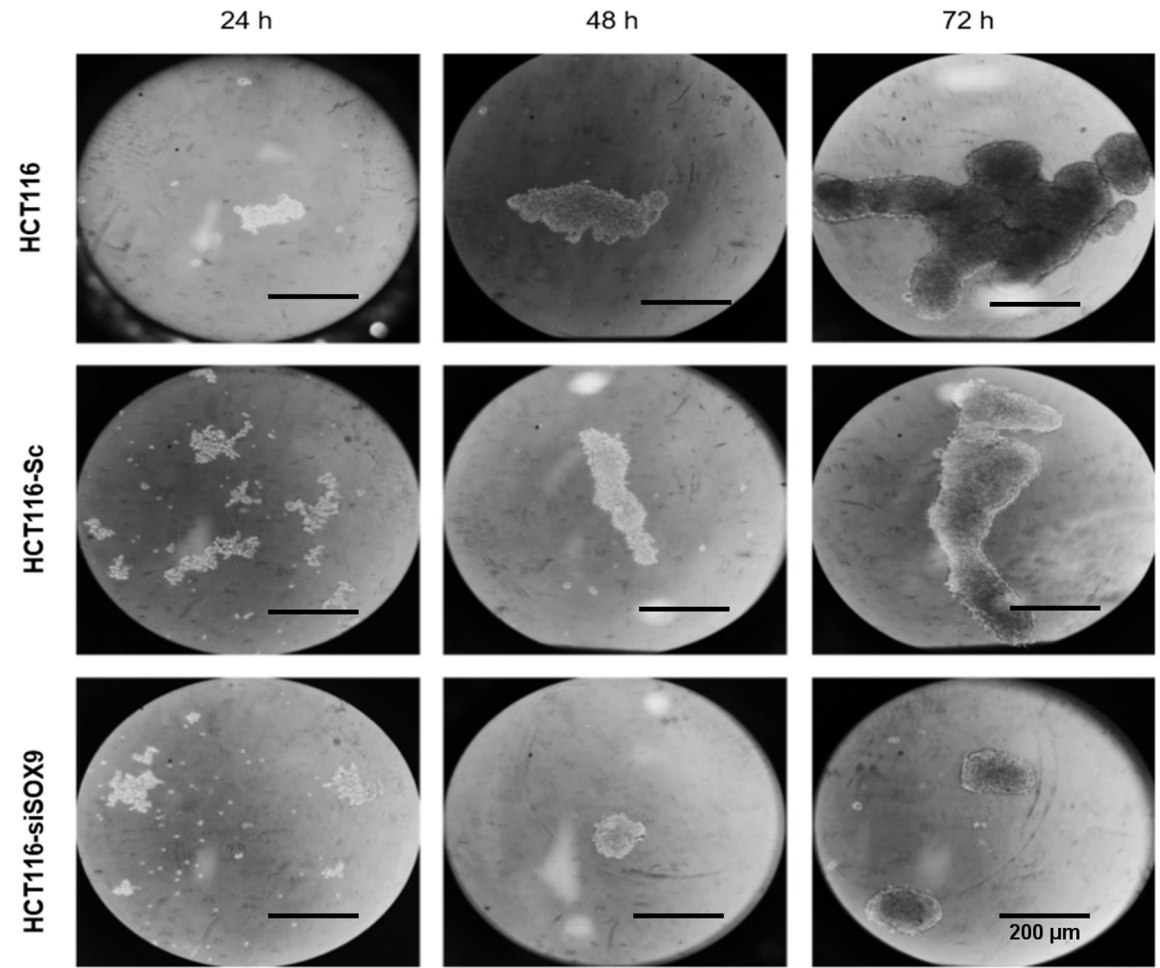

Figure 7. SOX9 silencing inhibits spheroid formation in a time dependent manner. HCT116 (line 1) and HCT116-Sc (line 2) cells could form spheroids at 24 and 72 h. HCT116-siSOX9 cells formed only labile cellular aggregates (line 3). Scale bar, $20 \mu \mathrm{m}$. SOX9, SRY-related high-mobility group box 9; HCT116-siSOX9, HCT116 cells transfected with small interfering RNA targeting SOX9; HCT116-Sc, HCT116 cells transfected with scrambled siRNA.

Herein, in vitro experiments revealed that the increased SOX9 expression could play an important role in tumorigenesis and clinically associate mainly with advanced T-stages in clinical-stage II patients, but not with relapse or 
survival. These findings were inconsistent with those reported by Maiken et al (27), where high and low levels of SOX9 in primary stage II colon tumors could predict low and high risk of relapse, respectively, suggesting that SOX9 could be used as a biomarker for predicting risk of relapse. Besides, Lü et al (19) demonstrated that SOX9 immunoreactivity was the same among different CRC stages. This finding could be attributed to the heterogeneity of CRC tumors among patients. Nevertheless, given the differences found in SOX9 expression in different studies, Prévostel and Blache (40) proposed a molecular model suggesting that in order to ensure a sustained proliferation of intestine epithelial cells, a critical level of active SOX9 should be maintained. In addition, according to this model, CRC cells can implement several strategies in order the levels of active SOX9 to be sufficient for cell proliferation, namely heterozygous inactivating mutations, regulation of SOX9 expression, and regulation of SOX9 activity, mediated by SOX9 binding proteins such as transcription factors (40). Nonetheless, more experimental work needs to be addressed to better understand the molecular mechanisms of SOX9 in CC.

Emerging evidence has suggested that higher SOX9 expression is associated with advanced pathological grade and different clinical stages in other types of cancer such as renal cell carcinoma and bladder cancer (38). These findings could explain the local recurrence mediated by SOX9 capability on inducing stemness state and chemoresistance. However, longer follow-up and a higher sample size are needed to further understand the effects of SOX9 in CC.

Intriguingly, the current study demonstrated that the expression levels of SOX9 were not associated with survival probability, neither in global $(\mathrm{P}<0.66)$ nor in relapsed patients $(\mathrm{P}<0.21)$. In this regard, there is evidence supporting that cancer therapy is not equally effective against all types of cancer, and cells that are not eliminated may contribute to residual disease and may be the key drivers of cancer relapse (41). Cancer stem cells (CSCs) could be responsible of this behavior since they are usually resistant to chemotherapy, eventually promoting recurrence $(42,43)$. Furthermore, the expression levels of SOX9 are associated with stemness phenotype, since SOX9 levels are sufficient to acquire and maintain colorectal-CSCs traits (23). In the present study, overexpressed SOX9 was predominant in the right side. These right-sided tumors (RSTs) tend to be advanced, bigger, and are often poorly differentiated. In addition, RSTs are associated with mutations in the DNA mismatch repair pathway, and do not respond well to conventional therapies, whereas they benefit from immunotherapy given their antigenic load $(44,45)$.

Furthermore, it has been reported that SOX9 expression is associated with chemoresistance in gastric $(46,47)$, pancreatic (48) and CRC, while its high expression in several solid tumors is associated with poor OS, RFS and disease-free survival (17). These results could suggest that SOX9 was not associated with survival probability, at least in a small cohort of patients as described here. However, it has been reported that higher levels of SOX9 are associated with reduced survival probability in hepatocellular carcinoma (49). Additionally, the expression of SOX9 has been previously associated with poor prognosis and RFS in different types of cancer (50). In terms of molecular characterization, frequent mutations in AT-rich interaction domain 1A, APC membrane recruitment protein 1 and SOX9 genes have been identified in CC and RC (51), supporting the diversity of SOX9 behavior in CC among different populations. These results indicated that SOX9 expression was not relevant to survival probability, suggesting that a larger number of patients should be analyzed to obtain a significant correlation.

Herein, SOX9 silencing attenuated the colonosphere formation ability of HCT116 cells, a hallmark of cancer stem cells. According to Bahmad et al, these studies primarily relied on two main criteria in their assessment: average volume of the generated spheres (size) and the average number of sphere-forming units (SFU) (52). Although our study did not evaluate SFU, size of colonosphere represents the proliferation of cells in the tumor mass, the capability of adhesion, and the anoikis resistance (AR) $(53,54)$. A study demonstrated that SOX9 silencing resulted in AR loss in HCT116 cells. Therefore, the AR tumor cells could detach from their primary tumor and metastasize $(52,55)$. During tumor onset, normal cells acquire mutations that modify the gene expression of specific genes, thus promoting a series of molecular changes, which in turn stimulate clonal expansion and the development of invasive properties of aberrant cells (56). It has been shown that the fusion of apoptotic blebs, retention of full-length p70S6K, pH, and lipid-dependent fusion between blebbishields to form spheres is a key aspect for survival of CSCs (57). Also, important downstream genes of the Wnt/ $\beta$-catenin signaling, such as SOX9, are involved in several crucial processes of cancer development, such as the long-term self-renewal and tumor formation, during the early steps (58). Emerging evidence has supported the inhibition of colonosphere formation in response to conditional expression of wild type SOX9, which also attenuates the activity of the Wnt/ $\beta$-catenin pathway (59). These results suggested that SOX9 could have a pivotal role in the generation of CSCs via modulating other molecules in the form of spheroids, as previously described in other types of cancer $(60,61)$. Nevertheless, the effect of SOX9 overexpression in SOX9-negative CRC cancer cells needs to be examined as well as the expression of p70S6 $\mathrm{k}$ as a marker of cell transformation in colonospheres to better support this hypothesis.

In conclusion, in the present study the expression levels of SOX9 were determined in Mexican patients diagnosed with early-stage CC and showed that SOX9 expression was associated with younger $\mathrm{CC}$ cases with advanced $\mathrm{T}$ stages of clinical stage II, but not with relapse or disease-free survival. However, further studies with a larger sample size are needed to assess the response of cells to the restoration of SOX9 expression to further understand the underlying molecular mechanisms involved in CRC.

\section{Acknowledgements}

Not applicable.

\section{Funding}

The authors acknowledge Consejo Nacional de Ciencia y Tecnología CONACYT (grant no. 290311) for funding. 


\section{Availability of data and materials}

All data generated or analyzed during this study are included in this published article.

\section{Authors' contributions}

ELV, MAF, MB and MPN conducted laboratory tests. TGC, EFF, HAS, IVS and ERG diagnosed and treated the patients. MAM, RRP and RCO collected the data and analyzed the results. LLS analyzed SOX9 expression in patients' samples. MAM, CLC and RRP conceived and designed the study. CLC and MAM confirmed the authenticity of the data. CLC, RRP, MB, MAM and ERG wrote the manuscript. All authors read and approved the final manuscript.

\section{Ethics approval and consent to participate}

The study protocol was approved by the Institutional Review Board of the National Cancer Institute of Mexico (permit no. Rev/42/16) and due to its retrospective nature, patient informed consent was not needed.

\section{Patient consent for publication}

Not applicable.

\section{Competing interests}

The authors declare that they have no competing interests.

\section{References}

1. Rawla P, Sunkara T and Barsouk A: Epidemiology of colorectal cancer: Incidence, mortality, survival, and risk factors. Prz Gastroenterol 14: 89-103, 2019.

2. Bray F, Ferlay J, Soerjomataram I, Siegel RL, Torre LA and Jemal A: Global cancer statistics 2018: GLOBOCAN estimates of incidence and mortality worldwide for 36 cancers in 185 countries. CA Cancer J Clin 68: 394-424, 2018.

3. Hawkes N: Cancer survival data emphasise importance of early diagnosis. BMJ 364: 1408, 2019.

4. Rojas-Puente L, de la Garza-Salazar JG, Calderillo-Ruiz G, Lino-Silva LS, Millan SV, Noveron NR, Meneses-Garcia A, de la Vega HA and Ruiz Garcia EB: Increased incidence of colorectal cancer in young people (less than 40 years old) over the last ten years. J Cancerology 1: 16-22, 2014.

5. Ahnen DJ, Wade SW, Jones WF, Sifri R, Mendoza Silveiras J, Greenamyer J, Guiffre S, Axilbund J, Spiegel A and You YN: The increasing incidence of young-onset colorectal cancer: A call to action. Mayo Clin Proc 89: 216-224, 2014.

6. Mishra DK, Veena U, Kaliki S, Kethiri AR, Sangwan VS, Ali MH, Naik MN and Singh V: Differential expression of stem cell markers in ocular surface squamous neoplasia. PLoS One 11: e0161800, 2016

7. Brenner H, Kloor M and Pox CP: Colorectal cancer. Lancet 383: 1490-1502, 2014

8. Li W, Zhang G, Wang HL and Wang L: Analysis of expression of cyclin E, p27kip1 and Ki67 protein in colorectal cancer tissues and its value for diagnosis, treatment and prognosis of disease. Eur Rev Med Pharmacol Sci 20: 4874-4879, 2016.

9. Krausova $M$ and Korinek V: Wnt signaling in adult intestina stem cells and cancer. Cell Signal 26: 570-579, 2014

10. Gassler N: Paneth cells in intestinal physiology and pathophysiology. World J Gastrointest Pathophysiol 8: 150-160, 2017.

11. Sailaja BS, He XC and Li L: The regulatory niche of intestinal stem cells. J Physiol 594: 4827-4836, 2016.

12. Jo A, Denduluri S, Zhang B, Wang Z, Yin L, Yan Z, Kang R, Shi LL, Mok J, Lee MJ, et al: The versatile functions of Sox9 in development, stem cells, and human diseases. Genes Dis 1: 149-161, 2014.
13. Bastide P,DaridoC,PannequinJ,KistR, Robine S,Marty-DoubleC, Bibeau F, Scherer G, Joubert D, Hollande F, et al: Sox9 regulates cell proliferation and is required for Paneth cell differentiation in the intestinal epithelium. J Cell Biol 178: 635-648, 2007.

14. Morin PJ, Sparks AB, Korinek V, Barker N, Clevers H, Vogelstein B and Kinzler KW: Activation of beta-catenin-Tef signaling in colon cancer by mutations in beta-catenin or APC. Science 275: 1787-1790, 1997.

15. Korinek V, Barker N, Morin PJ, van Wichen D, de Weger R, Kinzler KW, Vogelstein B and Clevers H: Constitutive transcriptional activation by a beta-catenin-Tcf complex in $\mathrm{APC}^{-/-}$colon carcinoma. Science 275: 1784-1787, 1997.

16. Javier BM, Yaeger R, Wang L, Sanchez-Vega F, Zehir A, Middha S, Sadowska J, Vakiani E, Shia J, Klimstra D, et al: Recurrent, truncating SOX9 mutations are associated with SOX9 overexpression, KRAS mutation, and TP53 wild type status in colorectal carcinoma. Oncotarget 7: 50875-50882, 2016.

17. Aguilar-Medina M, Avendaño-Félix M, Lizárraga-Verdugo E, Bermúdez M, Romero-Quintana JG, Ramos-Payan R, Ruíz-García E and López-Camarillo C: SOX9 stem-cell factor: Clinical and functional relevance in cancer. J Oncol 2019: 6754040, 2019.

18. Blache P, van de Wetering M, Duluc I, Domon C, Berta P, Freund JN, Clevers H and Jay P: SOX9 is an intestine crypt transcription factor, is regulated by the Wnt pathway, and represses the CDX2 and MUC2 genes. J Cell Biol 166: 37-47, 2004.

19. Lü B, Fang Y, Xu J, Wang L, Xu F, Xu E, Huang Q and Lai M: Analysis of SOX9 expression in colorectal cancer. Am J Clin Pathol 130: 897-904, 2008.

20. Shen Z, Deng H, Fang Y, Zhu X, Ye GT, Yan L, Liu H and Li G: Identification of the interplay between SOX9 and S100P in the metastasis and invasion of colon carcinoma. Oncotarget 6: 20672-20684, 2015.

21. Choi BJ, Park SA, Lee SY, Cha YN and Surh YJ: Hypoxia induces epithelial-mesenchymal transition in colorectal cancer cells through ubiquitin-specific protease 47-mediated stabilization of Snail: A potential role of Sox9. Sci Rep 7: 15918, 2017.

22. Zhang S, Che D, Yang F, Chi C, Meng H, Shen J, Qi L, Liu F, Lv L, Li Y, et al: Tumor-associated macrophages promote tumor metastasis via the TGF- $\beta$ /SOX9 axis in non-small cell lung cancer. Oncotarget 8: 99801-99815, 2017.

23. Carrasco-Garcia E, Lopez L, Aldaz P, Arevalo S, Aldaregia J, Egaña L, Bujanda L, Cheung M, Sampron N, Garcia I, et al: SOX9-regulated cell plasticity in colorectal metastasis is attenuated by rapamycin. Sci Rep 6: 32350, 2016.

24. Matheu A, Collado M, Wise C, Manterola L, Cekaite L, Tye AJ, Canamero M, Bujanda L, Schedl A, Cheah KS, et al: Oncogenicity of the developmental transcription factor Sox9. Cancer Res 72: 1301-1315, 2012.

25. Jay P, Berta P and Blache P: Expression of the carcinoembryonic antigen gene is inhibited by SOX9 in human colon carcinoma cells. Cancer Res 65: 2193-2198, 2005.

26. Zalzali H, Naudin C, Bastide P, Quittau-Prévostel C, Yaghi C, Poulat F, Jay P and Blache P: CEACAM1, a SOX9 direct transcriptional target identified in the colon epithelium. Oncogene 27: 7131-7138, 2008.

27. Marcker Espersen ML, Linnemann D, Christensen IJ, Alamili M, Troelsen JT and Høgdall E: SOX9 expression predicts relapse of stage II colon cancer patients. Hum Pathol 52: 38-46, 2016.

28. Lai CC, You JF, Yeh CY, Chen JS, Tang R, Wang JY and Chin CC: Low preoperative serum albumin in colon cancer: A risk factor for poor outcome. Int J Colorectal Dis 26: 473-481, 2011.

29. Boonpipattanapong $\mathrm{T}$ and Chewatanakornkul S: Preoperative carcinoembryonic antigen and albumin in predicting survival in patients with colon and rectal carcinomas. J Clin Gastroenterol 40: 592-595, 2006.

30. Dimitriou N, Arandjelović O, Harrison DJ and Caie PD: A principled machine learning framework improves accuracy of stage II colorectal cancer prognosis. NPJ Digit Med 1: 52, 2018.

31. Vera R, Aparicio J, Carballo F, Esteva M, González-Flores E, Santianes J, Santolaya F and Fernández-Cebrián JM: Recommendations for follow-up of colorectal cancer survivors. Clin Transl Oncol 21: 1302-1311, 2019.

32. van Diest PJ, van Dam P, Henzen-Logmans SC, Berns E, van der Burg ME, Green J and Vergote I; European Organization for Research and Treatment of Cancer-Gynaecological Cancer Cooperative Group: A scoring system for immunohistochemical staining: Consensus report of the task force for basic research of the EORTC-GCCG. J Clin Pathol 50: 801-804, 1997.

33. Livak KJ and Schmittgen TD: Analysis of relative gene expression data using real-time quantitative PCR and the 2(-Delta Delta $\mathrm{C}(\mathrm{T})$ ) method. Methods 25: 402-408, 2001. 
34. Lizárraga-Verdugo E, Ruiz-García E, López-Camarillo C, Bermúdez $M$, Avendaño-Félix $M$, Ramos-Payán $R$, Romero-Quintana G, Ayala-Ham A, Villegas-Mercado C, Pérez-Plasencia $\mathrm{C}$, et al: Cell curvival is regulated via SOX9/BCL2L1 axis in HCT-116 colorectal cancer cell line. J Oncol 2020: 5701527, 2020.

35. Wang L, He S, Yuan J, Mao X, Cao Y, Zong J, Tu Y and Zhang Y: Oncogenic role of SOX9 expression in human malignant glioma. Med Oncol 29: 3484-3490, 2012.

36. Mauri G, Sartore-Bianchi A, Russo AG, Marsoni S, Bardelli A and Siena S: Early-onset colorectal cancer in young individuals. Mol Oncol 13: 109-131, 2019.

37. Xicola RM, Manojlovic Z, Augustus GJ, Kupfer SS, Emmadi R, Alagiozian-Angelova V, Triche T Jr, Salhia B, Carpten J, Llor X, et al: Lack of APC somatic mutation is associated with early-onset colorectal cancer in African Americans. Carcinogenesis 39: 1331-1341, 2018.

38. Wan YP, Xi M, He HC, Wan S, Hua W, Zen ZC, Liu YL, Zhou YL, Mo RJ, Zhuo YJ, et al: Expression and clinical significance of SOX9 in renal cell carcinoma, bladder cancer and penile cancer. Oncol Res Treat 40: 15-20, 2017.

39. Mesquita P, Freire AF, Lopes N, Gomes R, Azevedo D, Barros R, Pereira B, Cavadas B, Pópulo H, Boaventura P, et al: Expression and clinical relevance of SOX9 in gastric cancer. Dis Markers 2019: 8267021, 2019.

40. Prévostel C and Blache P: The dose-dependent effect of SOX9 and its incidence in colorectal cancer. Eur J Cancer 86: 150-157, 2017.

41. Lytle NK, Barber AG and Reya T: Stem cell fate in cancer growth, progression and therapy resistance. Nat Rev Cancer 18: 669-680, 2018

42. Beck B and Blanpain C: Unravelling cancer stem cell potential. Nat Rev Cancer 13: 727-738, 2013.

43. Kusoğlu A and Biray Avcı C: Cancer stem cells: A brief review of the current status. Gene 681: 80-85, 2019.

44. Boland CR, Thibodeau SN, Hamilton SR, Sidransky D, Eshleman JR, Burt RW, Meltzer SJ, Rodriguez-Bigas MA, Fodde R, Ranzani GN, et al: A National Cancer Institute Workshop on Microsatellite Instability for cancer detection and familial predisposition: Development of international criteria for the determination of microsatellite instability in colorectal cancer. Cancer Res 58: 5248-5257, 1998.

45. Boland CR and Goel A: Microsatellite instability in colorectal cancer. Gastroenterology 138: 2073-2087.e3, 2010.

46. Santos JC, Carrasco-Garcia E, Garcia-Puga M, Aldaz P, Montes M, Fernandez-Reyes M, de Oliveira CC, Lawrie CH, Araúzo-Bravo MJ, Ribeiro ML, et al: SOX9 Elevation Acts with Canonical WNT Signaling to Drive Gastric Cancer Progression. Cancer Res 76: 6735-6746, 2016.

47. Wang J, Xue X, Hong H, Qin M, Zhou J, Sun Q, Liang H and Gao L: Upregulation of microRNA-524-5p enhances the cisplatin sensitivity of gastric cancer cells by modulating proliferation and metastasis via targeting SOX9. Oncotarget 8: 574-582, 2017.

48. Higashihara T, Yoshitomi H, Nakata Y, Kagawa S, Takano S, Shimizu H, Kato A, Furukawa K, Ohtsuka M and Miyazaki M: Sex determining region $\mathrm{Y}$ box 9 induces chemoresistance in pancreatic cancer cells by induction of putative cancer stem cell characteristics and its high expression predicts poor prognosis. Pancreas 46: 1296-1304, 2017.
49. Aguilar-Medina M, Avendaño-Félix M, Lizárraga-Verdugo E, Bermúdez M, Romero-Quintana JG, Ramos-Payan R, Ruíz-García E and López-Camarillo C: SOX9 stem-cell factor: Clinical and functional relevance in cancer. J Oncol 2019: 6754040, 2019.

50. Liu C, Liu L, Chen X, Cheng J, Zhang H, Shen J, Shan J, Xu Y, Yang Z, Lai M, et al: Sox9 regulates self-renewal and tumorigenicity by promoting symmetrical cell division of cancer stem cells in hepatocellular carcinoma. Hepatology 64: 117-129, 2016.

51. Network TCGA; Cancer Genome Atlas Network: Comprehensive molecular characterization of human colon and rectal cancer. Nature 487: 330-337, 2012.

52. Bahmad HF, Cheaito K, Chalhoub RM, Hadadeh O, Monzer A, Ballout F, El-Hajj A, Mukherji D, Liu YN, Daoud G, et al: Sphere-formation assay: Three-dimensional in vitro culturing of prostate cancer stem/progenitor sphere-forming cells. Front Oncol 8: 347, 2018.

53. Shaheen S, Ahmed M, Lorenzi F and Nateri AS: SpheroidFormation (Colonosphere) Assay for in vitro assessment and expansion of stem cells in colon cancer. Stem Cell Rev Rep 12: 492-499, 2016.

54. Terasaki M, Matsumoto N, Hashimoto R, Endo T, Maeda H, Hamada J, Osada K, Miyashita K and Mutoh M: Fucoxanthin administration delays occurrence of tumors in xenograft mice by colonospheres, with an anti-tumor predictor of glycine. J Clin Biochem Nutr 64: 52-58, 2019.

55. Rennebeck G, Martelli M and Kyprianou N: Anoikis and survival connections in the tumor microenvironment: Is there a role in prostate cancer metastasis? Cancer Res 65: 11230-11235, 2005.

56. Stratton MR: Exploring the genomes of cancer cells: Progress and promise. Science 331: 1553-1558, 2011.

57. Jinesh GG, Choi W, Shah JB, Lee EK, Willis DL and Kamat AM: Blebbishields, the emergency program for cancer stem cells: Sphere formation and tumorigenesis after apoptosis. Cell Death Differ 20: 382-395, 2013.

58. Larsimont J-C, Youssef KK, Sánchez-Danés A, Sukumaran V, Defrance M, Delatte B, Liagre M, Baatsen P, Marine JC, Lippens S, et al: Sox 9 controls self-renewal of oncogene targeted cells and links tumor initiation and invasion. Cell Stem Cell 17: 60-73, 2015.

59. Prévostel C, Rammah-Bouazza C, Trauchessec H, CanterelThouennon L, Busson M, Ychou M and Blache P: SOX9 is an atypical intestinal tumor suppressor controlling the oncogenic Wnt $/ \beta$-catenin signaling. Oncotarget 7: 82228-82243, 2016

60. Ma XL, Hu B, Tang WG, Xie S-H, Ren N, Guo L and Lu RQ: CD73 sustained cancer-stem-cell traits by promoting SOX9 expression and stability in hepatocellular carcinoma. J Hematol Oncol 13: 11, 2020.

61. Richtig G, Aigelsreiter A, Schwarzenbacher D, Ress AL, Adiprasito JB, Stiegelbauer V, Hoefler G, Schauer S, Kiesslich T, Kornprat P, et al: SOX9 is a proliferation and stem cell factor in hepatocellular carcinoma and possess widespread prognostic significance in different cancer types. PLoS One 12: e0187814, 2017.

This work is licensed under a Creative Commons Attribution-NonCommercial-NoDerivatives 4.0 International (CC BY-NC-ND 4.0) License. 